\title{
E-COLLABORATION IMPACTS IN AUSTRALIA AND HONG KONG
}

\author{
Deepinder Bajwa \\ Western Washington University \\ Email: Deepinder.Bajwa@wwu.edu \\ Floyd Lewis \\ Western Washington University \\ Email: Floyd.Lewis@wwu.edu \\ Graham Pervan \\ Curtin University \\ Email: g.pervan@curtin.edu.au \\ Vincent Lai \\ Chinese University of Hong Kong \\ Email: vslai@cuhk.edu.hk
}

\begin{abstract}
This paper investigates e-collaboration impacts across organizations in Australia and Hong Kong. The two regions were selected because of diversity in geographical dispersion and cultural differences. A myriad of e-collaboration activities were included in the study. Data collected and analyzed from 73 organizations in Australia and 94 organizations in Hong Kong suggests that there are no significant differences in the level of electronic support for collaboration activities in both the regions. However, significant differences were detected in the perceived impacts of e-collaboration between the two study regions. Interestingly, there was high level of agreement on ranking of ecollaboration activities and perceived e-collaboration impacts in both the regions. Implications of our findings for practice and research are discussed.
\end{abstract}

Keywords E-collaboration, collaboration technologies, collaboration tasks, collaboration impacts, technology use

\section{INTRODUCTION}

Broadly speaking e-collaboration can be defined as "collaboration among individuals engaged in a common task using electronic (and information) technologies" (Kock 2009). Practitioners have long recognized the importance of collaboration and recent and future trends suggested that e-collaboration is likely to continue to grow. According to IDC, the team collaboration applications market grew almost 15 percent during the first half 2012 (http://www.techworld.com.au/article/441245/idc_software_market_crm_virtualisation_collaboration _show_strongest_growth/). By some estimates, the global team collaboration and web conferencing market is expected to reach $\$ 19.97$ billion by the year 2015, a compound annual growth rate of $10.4 \%$. (http://www.researchandmarkets.com/reports/1721862/global_team_collaboration_software_and_aud io). 
Researchers have also been investigating e-collaboration (or collaborative information technologies) 3 for decades. There have been hundreds of studies collectively, exploring traditional collaboration technologies such as GSS (for a review, see Arnott and Pervan, 2005; Fjermestad and Hiltz, 20002001), videoconferencing (Webster, 1998), and proprietary groupware (for a review, see Karsten, 1999). Research on virtual team collaboration (for a review, see Karoui et al. 2010) point to the large amount of existing attention e-collaboration has received from academic researchers.

Despite the extant literature on e-collaboration, organizational level deployment of e-collaboration has received little attention and global comparisons are practically non-existent. In this paper, we systematically explore similarities and differences in e-collaboration and its impacts across organizations in Australia and Hong Kong. The two regions were selected not only because of the enormous difference between them in terms of the degree of geographical dispersion of people and organizations, but also because of their differences in cultural values. Of the five dimensions of cultural traits identified by Hofstede (1980), Australia and Hong Kong are comparable in the masculinity dimension, but differ significantly in individualism, power distance, uncertainty avoidance, and long term orientation traits.

\section{RESEARCH BACKGROUND}

At the organizational level, studies investigating e-collaboration and its impacts have been scarce and often limited in scope. An early study of Lotus Notes (a popular proprietary groupware CIT) in a large office within a service organization found that use of the technology did not match up to expectations (Orlikowski, 1992) and only lead to enhancements in personal productivity. Use of Notes was limited to emails, file transfers, and accessing news services rather than collaborating by cooperating and sharing information. Similar trends were observed by Vandenbosch and Ginzberg (1996-1997) who found that the introduction of Notes to support the professional staff of a large insurance company did not lead to any increase in collaboration over a six-month period. Users that had been collaborating prior to introduction of Notes continued to maintain their level of collaboration and users that did not collaborate continued to sustain their status. In a more comprehensive review of another 16 case studies investigating Notes, Karsten (1999) found that use and impacts of CIT may not be consistent across organizations. Results from a study of another CIT (desk-top videoconferencing) parallel those from studies of Lotus Notes. Although $100 \%$ of the employees had access to desk-top video conferencing 7 months after it was implemented, there was no notable increase in use levels of the technology after 12 months. In fact, for some users, use levels dropped in the last 5 months (Webster, 1998). Lou et al. (2006) studied the use and acceptance of Notes through three theoretical lens (media richness, social influence, and critical mass) and found only social influence had an impact on groupware use behavior, and that impact was only moderate.

More recent efforts exploring organizational impacts of e-collaboration suggest an increase in the firm's ability to innovate (Merono-Cerdan et al., 2008; Chen et al., 2009; Antikainen et al., 2010; Troshani et al., 2011), greater productivity (Ding et al., 2010), and improved financial performance (Chen et al., 2009). Further, the increased use of e-collaboration to replace travel has had a positive impact on

${ }^{3}$ Collaborative information technologies (CITs) are essentially IT applications that can support collaboration, which by definition implies e-collaboration. 
environmental friendliness and sustainability (Molla and Abareshi, 2012). In summary, the majority of the past research on organization-level e-collaboration and its impacts has focused primarily on a single collaboration technology in the context of a specific organization. Some recent studies have investigated adoption of multiple collaborative technologies across organizations (Bayo-Moriones and Lera-Lopez, 2007) and in several global regions (Bajwa et. al., 2008). However, there are not large scale investigations exploring e-collaboration activities and its impacts across organizations.

Recent practitioner research points to the notion that that collaboration technologies (VoIP, text messaging, screen sharing, video conferencing, and presence awareness tools) are becoming increasing popular globally and organizations that are deploying these IP-enabled advanced technologies are performing better than those that are not investing in them (Frost and Sullivan, 2009). In light of these practitioner findings, we specifically address the similarities and differences in e-collaboration activities and its impact between organizations in Australia and Hong Kong.

\section{THEORETICAL FOUNDATIONS}

From an information system (IS) or information technology (IT) use standpoint, the original DeLone and McLean (1992) model of success has been the premise of many research investigations. According to the authors, the partial model relationships suggest that IS/IT use leads to impacts (or net benefits) at the individual level and at the organizational level.

IT use, in general, has been conceptualized at the system level in many research investigations. For example past studies have focused on use of email systems, audio conferencing systems, video conferencing systems, group support systems, enterprise resource planning systems, decision support systems, and expert systems. Although such studies have increased our understanding of antecedents of system use, they do not fully capture the extent of deployment of the capabilities/functionalities of the IT system under investigation. For example, an email system may have the capabilities to support communication, information dissemination, schedule meetings, organize tasks, amongst others. However, studies investigating email use may not necessarily focus on the deployment of the functionality of email systems to support various e-collaboration activities. To better understand IT use, researchers have suggested a "function-centric" approach (Jasperson et. al., 2005) that focuses on the capabilities of the IT to support activities rather than the system as a whole. Our research adopts this premise to investigate e-collaboration.

\section{METHODOLOGY}

A hybrid approach (case studies and survey design) was selected for the research initiative. We conducted four case studies and then followed up with a survey. The first two case studies were conducted in the US. Our objective was to understand more about the implementation of e-collaboration technologies, how they are used, and their possible impacts on organizations. The two case study organizations varied significantly in the size and scope of their geographical operations. Telephone interviews were conducted with five managers in a large organization and one manager in a small organization. Each participant was sent a detailed document of our research agenda and sample semistructured questions. The average time of each interview was about forty-five minutes and all the interviews were recorded. This was followed by two case studies in Australia. A similar interview process was adopted except that the interviews were conducted face-to-face with the senior most IT executive in each of the two organizations. Average time for each interview was about sixty minutes. The conversations were recorded. In all the cases, we found that organizations typically use a myriad of technologies for a wide range of e-collaboration activities and the more impacts of ecollaboration are perceived as its scope increases from intra- to inter-organization. 
The outcomes of the case study provided inputs to our survey design. We adopted the approach suggested by Sethi and King (1991) to formulate item measures for the survey. After a review of the literature, we found no validated measures for our study constructs. Since most of our constructs had not been explored before in the context e-collaboration, we developed our own measures. Six researchers participated in developing these measures. All of them have been involved in collaboration research for nearly two decades. The researchers formulated relevant items from the practitioner and academic literature. Discussions were then initiated to determine the clarity of the formulated items and their measurement scales. The resulting survey instrument was then pilot tested in three Australian organizations. Two of these organizations were the same as our case study organizations. Feedback from the pilot study participants was used to make slight amendments to the original instrument. We next focus on the construct measures for our study constructs.

\section{MEASURES}

\section{E-collaboration Activities}

Paralleling the "function-centric" approach (Jasperson et al., 2005), we developed a measure of ecollaboration that reflected the extent to which key collaboration activities are supported by information technology. We reviewed the relevant literature (Easley et al., 2003; Hansen, and Jarvelin, 2005; Nunamaker, et al., 1996-1997; Karsten, 1999) to identify collaboration activities in order to formulate item measures. In addition to this, we tapped into our own experience to identify collaboration activities. These experiences were based on past research efforts and e-collaboration activities in our classes. We also evaluated selected collaboration technologies currently available on the market to identify key capabilities and activities that would be supported in e-collaboration. Based on these procedures, ten items that comprehensively captured collaboration activities were identified. These included: communications, information and knowledge sharing, decision-making, report writing/information pooling, planning, scheduling, progress monitoring, time management, issue resolution, and discussion and brainstorming. A five point scale ( $1=$ never used, $2,3=$ occasionally used, 4, 5 = always used) was deployed to measure the extent to which IT was used to support each of the ten collaboration activities in the organization.

\section{E-collaboration Impacts}

A review of past studies and other relevant literature (Applegate et al., 2006; Ahuja et al., 2009; Karsten, 1999; Kock, 2009; Thomas and Bostrom, 2006; Vandenbosch and Ginzberg, 1996-1997; Wasonga, 2007) identified eighteen different impacts. While fourteen of these impacts were desirable outcomes, four of them were negative outcomes of e-collaboration. Accordingly, we formulated fourteen items to measure the desired impacts and four items to measure adverse impacts. The desired impacts included: improvements in existing products/services, improved relationships with customers, suppliers, and business partners, improvements in existing business processes, structural changes, time savings, quick reaction to changes, speed of decision-making, increased productivity, appropriate responses to changes, facilitation of innovations, improved quality of decisions, and marketing the right products/services. The adverse impacts included: increased fragmentation of work, increased information overload, decreased management control, and decreased independence. A five point Likerttype scale (strongly disagree to strongly agree) was used for all the eighteen items to measure the level of agreement with each of the impacts resulting from e-collaboration in the organization. 


\section{DATA COLLECTION}

Data was collected in the two regions over a one year period. In the first stage, data collection was initiated in Australia. An email and a hard copy of the questionnaire was sent to CIOs of 500 of the top 1000 organizations in Australia. The email provided a link to the electronic version of the survey in case the participants preferred the option of responding online. A cover letter was included in the mailed surveys. This letter explained the purpose of our study. Clear instructions (including definition of IT supported collaboration, voluntary participation, confidentiality of responses etc.) for the participants were incorporated in the cover letter and they were requested to forward the survey to the executive most knowledgeable about IT-supported collaboration in their organization, if other than themselves. These instructions were also included on the web survey. A second hard copy mailing was sent out after about a month. A total of 83 responses (web and traditional mail) were received from Australian organizations. Sixty eight questionnaires were returned unopened possibly because the addressed executive could not be located. Ten survey responses were discarded due to substantial missing data. As a result, 73 usable responses were received from 432 questionnaires that reached the addressed executives. This represents a response rate of about $16.9 \%$. We conducted non-response bias tests and found no significant differences in majority of the item measures between the early and late respondents.

In Hong Kong, the questionnaire along with the same cover letter was mailed to senior MIS executives of the top 600 organizations. The first mailing resulted in responses from 48 organizations. One month later, the non-responding organizations were sent a reminding letter and another questionnaire, encouraging them to respond to our survey. The second round of mailing resulted in 29 completed responses. Two months later, another round of mailing was undertaken following similar procedures as in previous rounds. This resulted in another 17 responses. A total of 94 useable responses were received from organizations in Hong Kong. Thirty two questionnaires were undelivered and returned by the post office, resulting in a response rate of $16.5 \%$. We conducted non-response bias tests between the early and late respondents and found no significant differences in the majority of the item measures.

\section{RESULTS}

\section{Response profile}

Tables 1 and 2 compare the profile of our respondents (organization level and total number of employees in the organizations) across Australia and Hong Kong. The respondent positions from both the regions were re-coded into 3 tiers. Top tier included responses from Presidents, c-level executives (CIO, CFO, CEO, COO), directors, and vice presidents. Middle tier included responses from general managers, senior managers, functional area managers, system and database administrators, while the lower tier included responses from system analysts, IT specialists, senior systems engineers, senior software engineers, amongst others. Although our survey had been mailed to the CIO in all the Australian organizations and the senior MIS executive in organizations in Hong Kong, our respondents held a wide range of positions, indicating that the survey had actually been forwarded to the person that (in all probability) was most knowledgeable about IT supported collaboration work in their respective organizations. We received responses from small-medium enterprises and from large corporations. A wide range of industries were represented in the responses from both the regions. These included: aviation, manufacturing, financial services, engineering, utilities, education, oil and gas, mining, healthcare, government, legal services, retail, electronics, IT, defense, and leisure and entertainment amongst others. This reflects widespread deployment of e-collaboration across large and small organizations and in most (if not all) industries. 


\begin{tabular}{|l|l|l|}
\hline Organization Level & Australia [n = 68] & Hong Kong [n = 88] \\
\hline Top Tier & $25[36.8 \%]$ & $21[23.9 \%]$ \\
\hline Middle Tier & $39[57.4 \%]$ & $48[54.5 \%]$ \\
\hline Lower Tier & $4[5.9 \%]$ & $19[21.6 \%]$ \\
\hline
\end{tabular}

Table 1: Management Level of Respondents

\begin{tabular}{|l|l|l|}
\hline Number of Employees & Australia [n = 67] & Hong Kong [n = 83] \\
\hline Less than 100 & $11[16.4 \%]$ & $32[38.6 \%]$ \\
\hline 100 to 999 & $7[10.4 \%]$ & $13[15.7 \%]$ \\
\hline 1000 to 4999 & $36[53.7 \%]$ & $21[25.3 \%]$ \\
\hline More than 5000 & $13[19.4 \%]$ & $17[20.5 \%]$ \\
\hline
\end{tabular}

Table 2: Organization Size (number of employees) of Responding Firms

\section{DATA ANALYSIS}

\section{E-collaboration Activities}

Our review of the literature identified ten collaboration activities. Figure 2 shows the extent to which the ten collaboration activities are being supported by ITs in Australia and Hong Kong. The results indicate that ITs are used more frequently to support communications, information and knowledge sharing, report writing/information pooling, scheduling, and monitoring progress (in rank order) in both the study regions. On the other hand, discussion and brainstorming is the least supported activity. We conducted t-tests to explore any differences in the means of level of use of ITs to support collaboration activities between the two regions. The significant differences are also shown in Figure 2. The results indicate that ITs are used more frequently to support decision-making and issue resolution in Australian organizations than their counterparts in Hong Kong. 


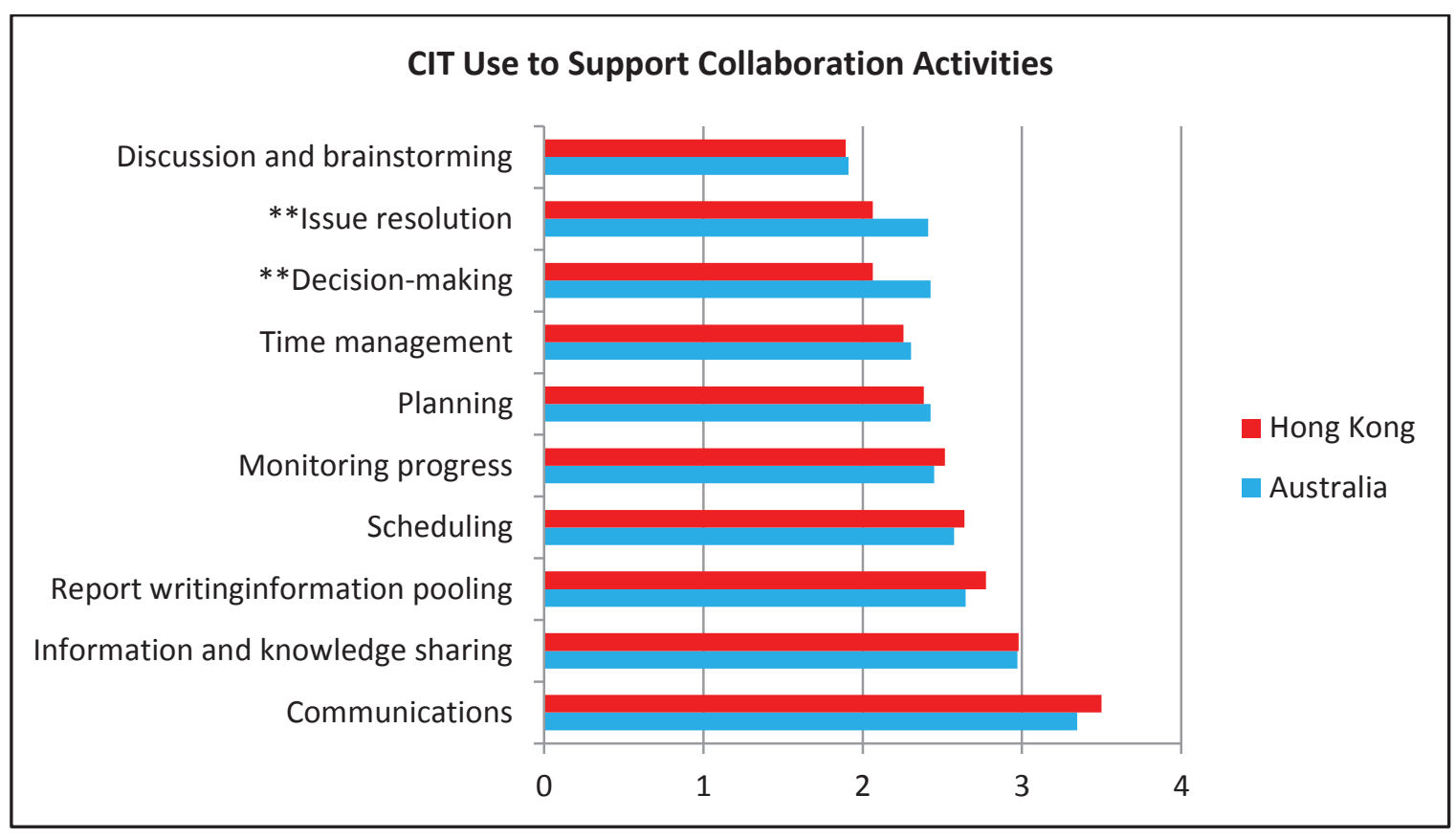

${ }^{* *} \mathrm{p}<0.05$

Figure 2: E-collaboration Activities

We computed Kendall's coefficient of concordance $(W)$ to statistically examine the average agreement in rankings of IT use to support various collaboration activities between the two regions (see Table 3). Kendall's $W$ can range from 0 - 1, where 0 indicates no agreement in rank order, and 1 indicates perfect agreement in rank order. Kendall's coefficient of $0.98(\mathrm{~F}=54, \mathrm{p}<0.001)$ indicates that there is a very high level of agreement between respondents in Hong Kong and Australia in terms of their rank order responses.

\begin{tabular}{|l|l|l|l|l|}
\hline \multirow{4}{*}{$\begin{array}{l}\text { Communications } \\
\text { Information and Knowledge Sharing }\end{array}$} & \multicolumn{2}{|c}{ Mean Response } & \multicolumn{2}{c|}{ Rank } \\
\cline { 2 - 5 } Report Writing/Information Pooling & 3.35 & 3.50 & 1 & 1 \\
\cline { 2 - 5 } $\begin{array}{l}\text { Scheduling } \\
\text { Monitoring Progress }\end{array}$ & 2.97 & 2.98 & 2 & 2 \\
\cline { 2 - 5 } $\begin{array}{l}\text { Planning } \\
\text { Time Management }\end{array}$ & 2.65 & 2.77 & 3 & 3 \\
\cline { 2 - 5 } Decision-making & 2.45 & 2.52 & 5 & 4 \\
\cline { 2 - 5 } Issue Resolution & 2.43 & 2.38 & 6 & 6 \\
\cline { 2 - 5 } Discussion and Brainstorming & 2.30 & 2.26 & 9 & 7 \\
\cline { 2 - 5 } & 2.43 & 2.06 & 7 & 8 \\
\cline { 2 - 5 } & 2.41 & 2.06 & 8 & 9 \\
\cline { 2 - 5 } & 1.91 & 1.89 & 10 & 10 \\
\hline
\end{tabular}

Table 3: Rank Order of E-collaboration Activities 


\section{E-collaboration Impacts}

Figure 3a below shows the level of agreement with the desired impacts resulting from e-collaboration. In general, companies in Hong Kong had higher level of agreement with these impacts than their counterparts in Australia. We conducted t-tests to explore any differences in means of level of agreement with these impacts between the two regions. The significant differences are also shown in Figure 3a. The results indicate that the majority of the impacts have significantly higher level of agreement in organizations in Hong Kong than their Australian counterparts. Interestingly, respondents in Australia had significantly higher level of agreement that use of e-collaboration facilitated innovations than respondents in Hong Kong.

Figure 3b shows the level of agreement with the adverse impacts resulting from e-collaboration. Once again, companies in Hong Kong had higher level of agreement with these impacts than their counterparts in Australia. We conducted t-tests to explore any differences in means of level of agreement with these impacts between the two regions. The significant differences are also shown in Figure 3b. The results indicate significantly higher level of agreement that e-collaboration increased information overload and increased fragmentation of work in organizations in Hong Kong than in Australia.

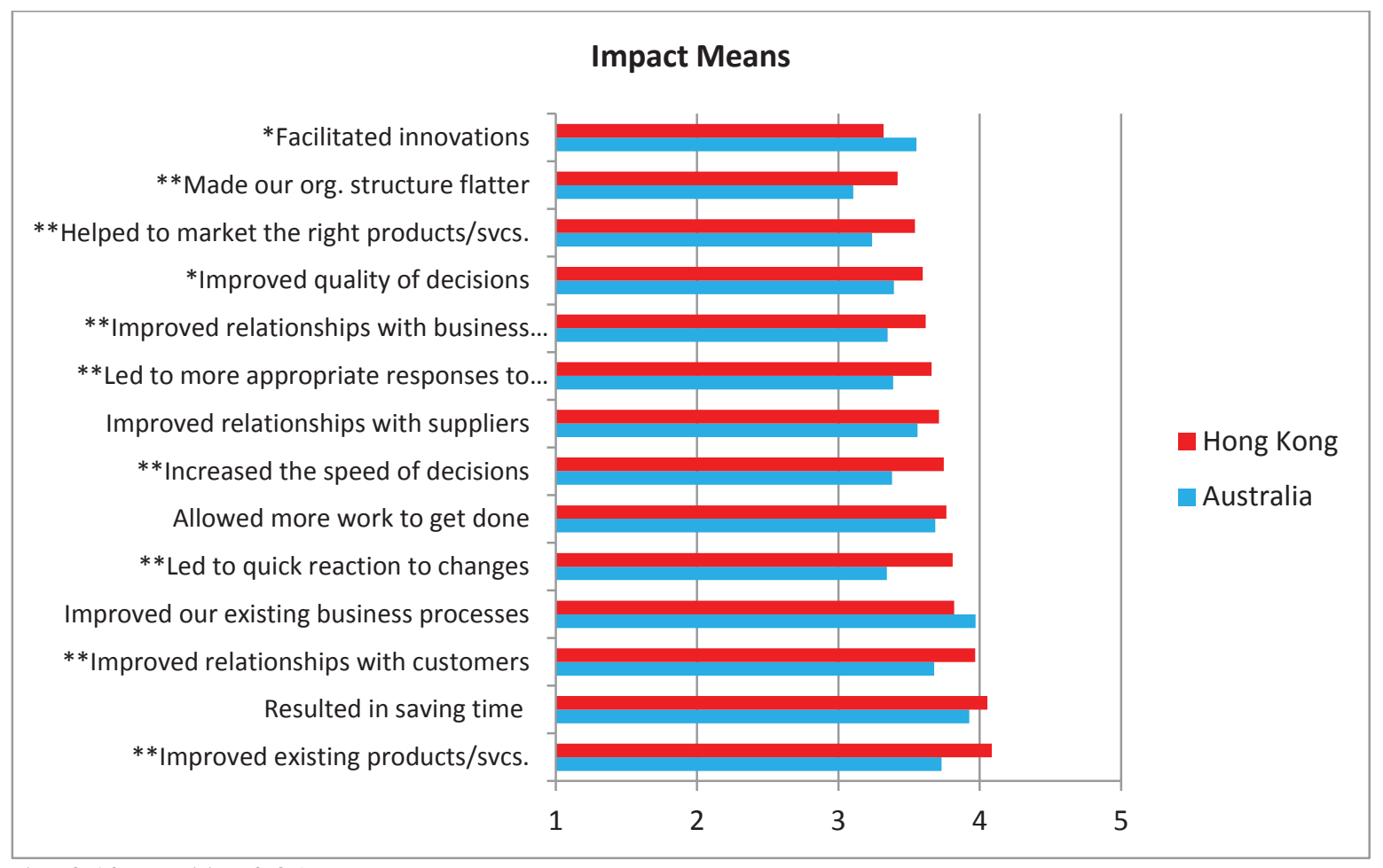

${ }^{*} \mathrm{p}<0.10 \quad * * \mathrm{p}<0.05$

Figure 3a: Desired E-collaboration Impacts 


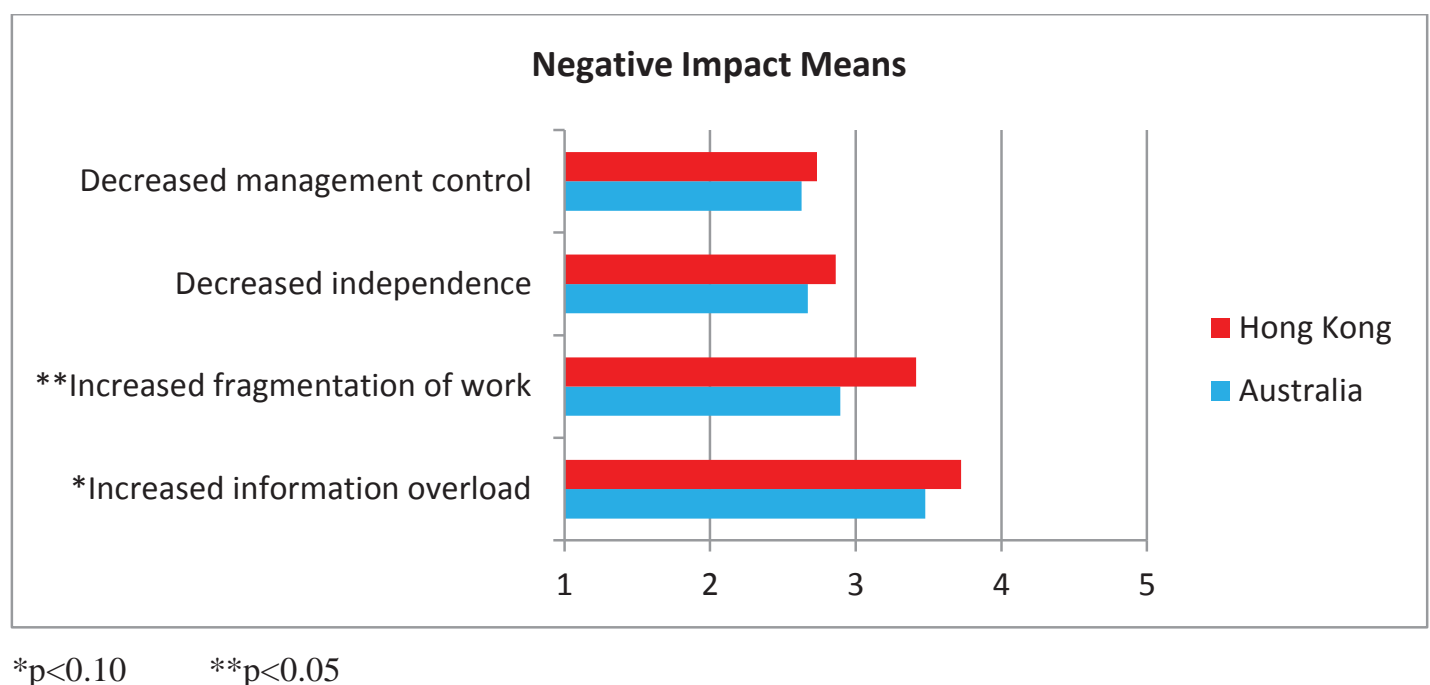

Figure 3b: Adverse E-collaboration Impacts

We computed Kendall's coefficient of concordance $(W)$ to statistically examine the average agreement in rankings of all the impacts of e-collaboration between the two regions (see Table 4). Kendall's coefficient of $0.895(\mathrm{~F}=8.5, \mathrm{p}<0.005)$ indicates a high level of agreement between respondents in Hong Kong and Australia in terms of their rank order of impacts. However, it is interesting to note that there were some large differences in the ranking for a few items: "Quick reaction to changes" was ranked much higher in Hong Kong than in Australia while "Facilitated innovations" was ranked much higher in Australia than in Hong Kong. 


\begin{tabular}{|c|c|c|c|c|}
\hline & \multicolumn{2}{|c|}{ Mean Responses } & \multicolumn{2}{|c|}{$\begin{array}{l}\text { Rank } \\
\text { Hong }\end{array}$} \\
\hline Improved existing products/services & 3.73 & 4.09 & 3 & 1 \\
\hline Time savings to accomplish tasks & 3.93 & 4.05 & 2 & 2 \\
\hline Improved relationships with customers & 3.68 & 3.97 & 5 & 3 \\
\hline Improved existing business processes & 3.97 & 3.82 & 1 & 4 \\
\hline Quick reaction to changes & 3.34 & 3.81 & 13 & 5 \\
\hline More work accomplished & 3.69 & 3.76 & 4 & 6 \\
\hline Faster decision-making & 3.38 & 3.74 & 11 & 7 \\
\hline Increased information overload & 3.48 & 3.72 & 8 & 8 \\
\hline Improved relationships with suppliers & 3.56 & 3.71 & 6 & 9 \\
\hline More appropriate changes to responses & 3.39 & 3.66 & 10 & 10 \\
\hline Improved relationships with business partners & 3.35 & 3.62 & 12 & 11 \\
\hline Improved the quality of decisions & 3.39 & 3.60 & 9 & 12 \\
\hline Helped market right products/services & 3.24 & 3.54 & 14 & 13 \\
\hline Flatter organization structure & 3.11 & 3.42 & 15 & 14 \\
\hline Increased fragmentation of work & 2.90 & 3.41 & 16 & 15 \\
\hline Facilitated innovations & 3.55 & 3.32 & 7 & 16 \\
\hline Decreased independence & 2.67 & 2.86 & 17 & 17 \\
\hline Decreased management control & 2.63 & 2.73 & 18 & 18 \\
\hline
\end{tabular}

Table 4: Rank Order of E-collaboration Impacts

\section{DISCUSSION}

The objectives of this paper were to explore e-collaboration and its impacts across organizations in Australia and Hong Kong. We next turn to the discussion of our results from analyses of data to address each of the research objectives.

\section{E-collaboration Activities}

E-collaboration has several dimensions (i.e. it includes multiple activities) and our results confirm these findings in both the study regions. We also found that there was high agreement on e-collaboration activities in Australian and Hong Kong organizations. Since e-collaboration activities vary in the extent to which technology is used to support them, it may be possible to identify "primary" and "secondary" components of collaboration. The top five most frequently IT supported collaboration activities across both the study regions included: communications, information and knowledge sharing, report writing/information pooling, scheduling, and monitoring progress. These could well be the primary collaboration activities that are supported by ITs. Other activities that are less supported could well be secondary collaboration activities. 
Significant differences were detected in decision-making and issue resolution in e-collaboration between Australian organizations and their counterparts in Hong Kong. This could be attributed to organization size and structure. Although most of the responding companies in Hong Kong were multinational corporations, a significant portion of them were family-owned businesses. These latter types of organizations normally have a more centralized decision structure (and therefore depend less on ITsupported decision making) as family members or close relatives hold top management positions, thereby permitting rapid decision making and avoidance of 'agency' problems that confront Western organizations (Weidenbaum 1996). The decision making style in these organizations is more directive and authoritarian, thus requiring less distributed decision collaboration and issue resolution. For the Australian organizations, many decisions and issues are at the operational level and need to be resolved by people who are far apart geographically. They are thus more reliant on ITs for collaboration rather than face-to-face contact. More frequent use of ITs to support decision-making and issue resolution in Australian organizations may also be reflective of the wide geographical dispersion of employees across states (Sydney and Melbourne are both over 4,000 km from Perth, for example). This dispersion is even more significant for Australian mining companies (which are well represented in the Australian sample) where, even when in the same state, headquarters and operations may be over $1,500 \mathrm{~km}$ apart, thus necessitating the use of ITs to make decisions and resolve issues.

\section{E-collaboration Impacts}

E-collaboration can lead to organization-wide impacts and our findings detected many of these impacts in both the study regions. Once again, we also found significantly high agreement on ranking of impacts in Australian and Hong Kong organizations. The five highest ranking impacts where agreement levels were also high included: improved existing products/services, time savings to accomplish tasks, improved relationships with customers, improved existing business processes, and more work accomplished as a result of e-collaboration. Thus respondents in both the study regions perceive that ecollaboration can result in strategic and operational level effectiveness and efficiency-oriented impacts. The five lowest ranking impacts where agreement levels were also low included: helped to market right products/services, flatter organization structure, increased fragmentation of work, decreased independence, and decreased management control. Three of these five lowest ranking impacts were "adverse impacts", thereby suggesting that the desired e-collaboration impacts far outweigh the undesired consequences with the exception of "information overload," which was ranked eighth in both the study regions. This is an issue of concern as information overload due to mass interaction is likely to end active participation by users (Jones et al., 2004). This may be especially critical when organizations adopt technologies to support online communities for their collaboration activities.

We also found significant differences in ten of the eighteen impacts between organizations in Australia and Hong Kong. In almost all the cases, organizations in Hong Kong had significantly higher level of agreement towards desired and adverse impacts than their Australian counterparts. Although there are very few significant differences in the e-collaboration activities in organizations between the two regions (significant differences were detected only for decision making and issue resolution), other forces may be in play to explain the differences in impacts. One possible explanation is that end-users in Hong Kong have a significantly greater level of influence in implementing e-collaboration than in Australia. This offers more opportunities for users to experiment with the usefulness of IT tools in enhancing their collaborative activities. Some ITs are complex and multi-faceted, making it difficult for users to comprehend their impacts when they are deployed. Therefore, "learning by using" allows users to develop an understanding of the strengths and weaknesses of the technology. As a consequence, e-collaboration in Hong Kong has developed a steeper learning curve, thus resulting in their creation of new knowledge (Alder and Clark 1991; Faraj et al., 2011) to use ITs to collaborate more effectively and efficiency. In the end, these users may also develop a stronger feeling of how collaborative tools could impact their jobs and organizations, in both the positive and negative ways. 
The causes for higher agreement in the majority of the impacts could also be attributed to other factors including, the reach of e-collaboration in Hong Kong organizations and the time lag of collecting data in in Hong Kong.

We also found significantly higher level of agreement that e-collaboration in Australian organizations "facilitated innovations" than in their counterparts in Hong Kong. This may be reflective of a greater mix of organizational sizes in Hong Kong. There were a greater proportion of small organizations represented in the Hong Kong sample (including family owned businesses). The centralized decision structure of these small family owned organizations may have limited innovative behavior and any related impacts. As for the Australian sample, higher impact levels for facilitating innovations may be due to the influence of mining companies which are known to be highly innovative users of all ITs.

Nevertheless, general trends indicate that organizations in both regions have realized significant impacts from e-collaboration. This suggests that, for the most part, organizations have the necessary elements (culture of openness and information sharing, structural elements, governance systems etc.) aligned well to facilitate e-collaboration. This may be more prominent in Hong Kong (than in Australia) as respondents indicated higher agreement levels on the majority of the impacts.

\section{CONCLUSIONS}

In this paper, we have explored e-collaboration activities and its impacts across organizations in Australia and Hong Kong. Given the exploratory nature of the research, our objective was not to propose and test relationships between our study constructs. Instead, it was our intent to extend and expand the existing literature on e-collaboration by comparing trends in under-investigated global regions. The two study regions selected vary significantly along cultural and geographical dimensions. Despite this diversity, we found many common trends that have important implications for practice and research.

From the practitioner standpoint, our findings provide benchmarks to assess e-collaboration activities and the organizational level impacts resulting from e-collaboration. Organizations use ITs to support many collaboration activities. Benchmarks can assist practitioners in their regions to identify ecollaboration opportunities in their respective organizations. An assessment of e-collaboration impacts may also encourage practitioners to justify investments in order to become more competitive.

From a research standpoint, this study contributes to our understanding about e-collaboration activities and its impacts across organizations in two global regions. Most e-collaboration studies have focused on a single technology in a specific organization. Our study focused on several activities that could be supported by many different technology solutions. Such a functional-centric approach provides more in-depth understanding of e-collaboration as it is independent of the technology platforms used to support the phenomenon. The high agreement in rank order of e-collaboration activities in both the study regions supports the notion that collaboration can be viewed as a set of activities that are consistent across national boundaries. Future research could further explore "primary" and "secondary" e-collaboration activities and their impacts in other global regions. A more detailed assessment of the effects of e-collaboration on impacts can also be made by conducting additional longitudinal investigations. This would help explain the directional or differential effect between e-collaboration and its impacts over time.

While our study has extended and expanded the existing literature on e-collaboration, we must also recognize the limitations of our research. First, a single respondent in each organization was used to collect data on organizational level constructs. Although care was taken to reach the person most knowledgeable about the study objectives, single respondent perceptions about organizational level constructs can be problematic even though they have been used extensively in many IT studies. 
However, 85\% of our respondents were top and middle tier executives. Given that these informants are likely to have access to information about organizational level phenomenon in most modern organizations adds credibility to the responses. Second, data collection in the two study regions took place over a year and there could be "lag" effects of e-collaboration deployment and its impacts. Despite these limitations, our research makes significant contributions to the existing literature.

\section{REFERENCES}

Ahuja, V., Yang, J., \& Shankar, R. (2009). Benefits of collaborative ICT adoption for building project management. Construction Innovation, 9(3), 323-340.

Alder, P.S., \& Clark, K.B. (1991). Behind the learning curve: A sketch of the learning process. Management Science, 37(3), 267-281.

Antikainen, M., Makipaa, M., \& Ahonen, M. (2010). Motivating and supporting collaboration in open innovation. European Journal of Innovation Management, 13(1), 100-119.

Applegate, L.M., Austin, R., \& McFarlan, F.W. (2006). Corporate Information Strategy and Management: Text and Cases. Boston, MA: Irwin/McGraw-Hill.

Arnott, D., \& Pervan, G. (2005). A critical analysis of decision support systems research. Journal of Information Technology, 25(2), 67-87.

Asproth, V., \& Nystrom, C.A. (2008). Communication and information exchange among SMEs and their local environment. Journal of Organisational Transformation and Social Change, 5(2), 175-189.

Bajwa, D.S., Lewis, L.F., Pervan, G., Lai, V.S., Munkvold, B.E., \& Schabe, G. (2008). Factors in the global assimilation of collaborative information technologiies: An exploratory investigation in five regions. Journal of Management Information Systems, 25(1), 131-165.

Bayo-Moriones, A., \& Lera-Lopez, F. (2007). A firm-level analysis of determinants of ICT adoption in Spain. Technovation, 27(6-7), 352-366.

Camarinha-Matos, L.M., Afsarmanesh, H., Galeano, N., \& Molina, A. (2009). Collaborative networked organizations - concepts and practice in manufacturing enterprises. Computers \& Industrial Engineering, 57, 46-60.

Chen, J.S., Tsou, H.T., \& Huang, A.Y.H. (2009). Service delivery innovation: Antecedents and impact on firm performance. Journal of Service Research, 12(1), 36-55.

DeLone, W.H., \& McLean, E.R. (1992). Information systems success: The quest for the dependent variable. Information Systems Research, 3(1), 60-95.

Ding, W.W., Levin, S.G., Stephan, P.E., \& Winkler, A.E. (2010). The impact of information technology on academic scientists' productivity and collaboration patterns. Management Science, 56(9), 1439-1461.

Easley, R.F., Devaraj, S., \& Crant, J.M. (2003). Relating collaborative technology use to teamwork quality and performance: an empirical analysis. Journal of Management Information Systems, 19(4), 247-268.

Faraj, S., Jarvenpaa, S.L., \& Majchrzak, A. (2011). Knowledge collaboration in online communities. Organization Science, 22(5), 1224-1239.

Fjermestad, J., \& Hiltz, S.R. (2000-2001). Group support systems: A descriptive evaluation of case and field studies. Journal of Management Information Systems, 17(3), 115-159.

Hansen, P., \& Jarvelin, K. (2005). Collaborative information retrieval in an information-intensive domain. Information Processing \& Management, 41(5), 1101-1119. 
Hofstede, G. (1980). Culture's consequences: International differences in work-related values. Newbury Park, CA: Sage.

Jasperson, J., Carter, P.E., \& Zmud, R.W. (2005). A comprehensive conceptualization of post-adoptive behaviors associated with information technology enabled work systems. MIS Quarterly, 29(3), 525-557.

Jones, Q., Ravid, G., \& Rafaeli, S. (2004). Information overload and the message dynamics of online interaction spaces: A theoretical model and empirical exploration. Information Systems Research, 15(2), 194-210.

Karoui, M., Gurkan, A., \& Duderzet, A. (2010). Virtual team collaboration: A review of literature and perspectives. Proceedings of the Sixteenth Americas Conference on Information Systems, Lima, Peru, August 12-15, 2010.

Karsten, H. (1999). Collaboration and collaborative information technologies: A review of the evidence. DATABASE for Advances in Information Systems, 30(2), 44-65.

Kock, N. (2009). The evolution of costly traits through selection and the importance of oral speech in e-collaboration. Electronic Markets, 19, 221-232.

Lou, H., Scamell, R., \& Shah, J.R. (2006). Use of a groupware product: A test of three theoretical perspectives. Journal of Computer Information Systems, 46(4), 35-45.

Meroño-Cerdán, A.L., Soto-Acosta, P., \& López-Nicolás, C. (2008). How do collaborative technologies affect innovation in SMEs? International Journal of E-Collaboration, 4(4), 33-50.

Molla, A., \& Abarsehi, A. (2012). Organizational green motivations for information technology: Empirical study. Journal of Computer Information Systems, 52(3), 92-102.

Ngwenyama, O.K. (1998). Groupware, social action and organizational emergence: On the process dynamics of computer mediated distributed work. Accounting, Management and Information Technologies, 8(2-3), 127-146.

Nunamaker Jr, J.F., Briggs, R.O., Mittleman, D.D., Vogel, D.R., \& Balthazard, P. (1996-1997). Lessons from a dozen years of group support systems research: A discussion of lab and field findings. Journal of Management Information Systems, 13(3), 163-207.

Orlikowski, W.J. (1992). The duality of technology: Rethinking the concept of technology in organizations. Organization Science, 3, 298-327.

Sethi, V., \& King, W.R. (1991). Construct measurement in information systems research: An illustration in strategic systems. Decision Sciences, 22(3), 455-463.

Thomas, D., \& Bostrom, R. (2006). Building trust and cooperation through technology adaptation in virtual teams: Empirical field evidence. Information Systems Management, 25, 45-56.

Troshani, I., Rampersad, G., \& Plewa, C. (2011). Adopting innovation management software in university innovation commercialization. Journal of Computer Information Systems, 52(2), 8392.

Vandenbosch, B., \& Ginzberg, M.J. (1996-97). Lotus Notes and collaboration: Plus ça change. Journal of Management Information Systems, 13(3), 65-81.

Wasonga, T.A. (2007). Using technology to enhance collaborative learning. International Journal of Educational Management, 21(7), 585-592.

Webster, J. (1998). Desktop videoconferencing: Experiences of complete users, wary users, and nonusers. MIS Quarterly, 22(3), 257-286.

Weidenbaum, M. (1996). The Chinese family business enterprise. California Management Review, 38(4), 141-156. 